
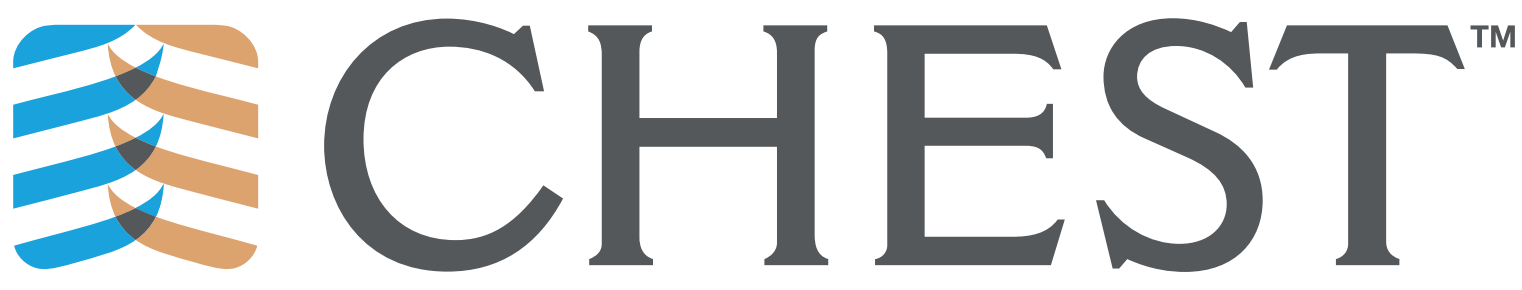

OFFICIAL PUBLICATION OF THE AMERICAN COLLEGE OF CHEST PHYSICIANS

\title{
ONLINE FIRST
}

This is an Online First, unedited version of this article. The final, edited version will appear in a numbered issue of CHEST and may contain substantive changes. We encourage readers to check back for the final article. Online First papers are indexed in PubMed and by search engines, but the information, including the final title and author list, may be updated on final publication.

http://journal.publications.chestnet.org/

Online First articles are not copyedited prior to posting.

CAmerican College of Chest Physicians.

Reproduction of this article is prohibited without written permission from the American College of Chest Physicians. See online for more details. 
Word Count: Text - 2,500; Abstract - 250

\section{Postoperative Complications in Patients with Unrecognized Obesity Hypoventilation Syndrome Undergoing Elective Non-cardiac Surgery}

Running head: Postoperative complications in OHS

Roop Kaw MD ${ }^{1,2}$; Priyanka Bhateja $\mathrm{MD}^{1}$; Hugo Paz y Mar MD ${ }^{3}$; Adrian V. Hernandez MD $\mathrm{PhD}^{4,5}$; Anuradha Ramaswamy $\mathrm{MD}^{6}$; Abhishek Deshpande $\mathrm{MD} \mathrm{PhD}^{1}$ and Loutfi S. Aboussouan $\mathrm{MD}^{3}$

${ }^{1}$ Medicine Institute and ${ }^{2}$ Department of Outcomes Research, Anesthesiology ${ }^{3}$ Respiratory Institute, ${ }^{4}$ Health Outcomes and Clinical Epidemiology Section, Department of Quantitative Health Sciences, Lerner Research Institute, Cleveland Clinic, Cleveland, Ohio, United States and ${ }^{5}$ Postgraduate and Medical Schools, Universidad Peruana de Ciencias Aplicadas (UPC), Lima, Peru, ${ }^{6}$ Department of Pulmonary \& Critical Care, Yale University.

Correspondence: Roop Kaw MD, Department of Hospital Medicine, Desk A13, Cleveland Clinic, 9500 Euclid Avenue, Cleveland, OH 44195 USA.

Conflict of Interest: No authors have any relevant conflicts of interest. Dr. Deshpande has received grant funding from $3 \mathrm{M}$.

Sources of funding: None 


\section{Abstract}

Background: Among patients with obstructive sleep apnea (OSA) a higher number of medical morbidities are known to be associated with those that have obesity hypoventilation syndrome (OHS) compared to OSA alone. OHS can therefore pose a higher risk of postoperative complications after elective non-cardiac surgery (NCS) and is often unrecognized at the time of surgery. The objective of this study was to retrospectively identify patients with OHS and compare their postoperative outcomes with those who have OSA alone.

Methods: Patients meeting criteria for OHS were identified within a large cohort of patients with OSA who underwent elective NCS at a major tertiary care center. We identified postoperative outcomes associated with OSA and OHS as well as the clinical determinants of OHS (BMI, AHI). Multivariable logistic or linear regression models were used for dichotomous or continuous outcomes, respectively.

Results: Patients with hypercapnia from definite or possible OHS, and overlap syndrome are more likely to develop postoperative respiratory failure [OR: 10.9 (95\% CI 3.7-32.3), $\mathrm{p}<0.0001$ ], postoperative heart failure $(\mathrm{p}<0.0001)$, prolonged intubation [OR: 5.4 (95\% CI 1.9-15.7), $\mathrm{p}=0.002)$, postoperative ICU transfer (OR: 3.8 (95\% CI 1.7-8.6), $\mathrm{p}=0.002]$; longer ICU (beta coefficient: 0.86; SE: 0.32, $\mathrm{p}=0.009$ ) and hospital length of stay (beta coefficient: 2.94; SE: 0.87 , $\mathrm{p}=0.0008$ ) when compared to patients with OSA. Among the clinical determinants of OHS, neither BMI nor AHI showed associations with any postoperative outcomes in univariable or multivariable regression.

Conclusions: Better emphasis is needed on preoperative recognition of hypercapnia among patients with OSA or overlap syndrome undergoing elective NCS. 


\section{Abbreviations List:}

Arterial Blood Gas $\quad$ ABG

Apnea Hypopnea Index AHI

American Society of Anesthesiologists ASA

Body Mass Index BMI

Cleveland Clinic Health System CCHS

Congestive Heart Failure CHF

Confidence Interval CI

Chronic Obstructive Pulmonary Disease COPD

Chronic Renal Failure CRF

Congestive Heart Failure $\quad$ CHF

Coronary Artery Disease CAD

Diabetes Mellitus DM

Electronic Medical Records EMR

General Anesthesia GA

Interquartile Range $\quad$ IQR

Myocardial Infarction $\quad$ MI

Non-cardiac Surgery NCS

Obesity Hypoventilation Syndrome OHS

Obesity Surgery Mortality Risk Score OS-MRS

Odds Ratio OR

Obstructive Sleep Apnea OSA

Positive Airway Pressure PAP 


\section{Page 3 of 25}

Polysomnography PSG

Pulmonary Function Test PFT

Standard Deviation $\quad$ SD 


\section{INTRODUCTION}

Based on a small cohort studies the prevalence of obesity hypoventilation syndrome (OHS) in the general population has been reported to be around $0.3-0.4 \% .{ }^{1}$ Among the only surgical series to report prevalence of OHS is a recent report from premenopausal women presenting for bariatric surgery with $8 \%$ prevalence of OHS. ${ }^{2}$ Among patients with known obstructive sleep apnea (OSA) the reported prevalence of OHS is between 10-20\% and known to increase with obesity to as high as $50 \%$ as the body mass index (BMI) exceeds $50 \mathrm{~kg} / \mathrm{m}^{2}{ }^{3}$ OHS is usually associated with many medical co-morbidities and often undiagnosed or undertreated before elective non-cardiac surgery (NCS). The main aims of this study are 1) to characterize the types of postoperative complications associated with elective NCS among patients with known or undiagnosed OHS and 2) to evaluate their association with the main defining characteristics of OHS i.e, BMI, hypercapnia and apnea hypopnea index (AHI).

\section{METHODS}

The study protocol was approved by the Institutional Review Board of Cleveland Clinic Health System (CCHS) \# 12-625.

I. Cohort identification

A retrospective cohort study was performed with CCHS data obtained with the help of Explorys Inc. (Cleveland, OH). The Explorys platform provides access to anonymous patient information and can create a large database of electronic medical records (EMR), allowing for large-scale population studies. The database was queried for all patients with $\mathrm{BMI} \geq 30$ who underwent polysomnography (PSG), NCS and had arterial blood gases (ABGs) drawn on more than one occasion throughout the CCHS. Laboratory records of ABGs done at different times in the 
course of these patients' pre-operative course and inter-operative periods were obtained and used as the basis of our inclusion criteria as outlined below to identify the cohort of patients with definite and possible OHS.

Ia. Inclusion criteria:

1. Patients with $\mathrm{BMI}>30$

2. Patients diagnosed with OSA by PSG at any time before and within 5 years after surgery

3. Patients with 'arterial hypercapnia' $(\mathrm{PaCo} 2 \geq 45 \mathrm{mmHg})$ at two separate intervals prior to NCS; single recorded hypercapnia before surgery with persistent hypercapnia ( $\geq 2$ recorded) values at two separate intervals >30 days apart after NCS; or hypercapnia observed postoperatively on two separate ABGs preceding the index surgery

4. Patients undergoing elective NCS

Among patients selected with above inclusion criteria, those with $\mathrm{BMI} \geq 30 ; \mathrm{AHI} \geq 5 ; \mathrm{PaCo}_{2} \geq$ $45 \mathrm{mmHg}$ and absence of significant lung disease including chronic obstructive pulmonary disease (COPD) $\left(\mathrm{FEV}_{1} / \mathrm{FVC}<70 \%\right)$ and very severe restrictive lung disease $(\mathrm{FVC}<30 \%)^{4,5}$ were identified as 'definite OHS'. To identify patients with 'possible OHS' data were collected even among patients who had missing pulmonary function test (PFT) information as long as they met the inclusion criteria for the study. Patients who met the first three inclusion criteria and underwent NCS were labeled as 'hypercapnic OSA'. Patients with OSA (inclusion criterion \#2) undergoing NCS who did not meet the ABG criteria were labeled as 'OSA' (Figure 1). For patients who underwent multiple surgeries, procedures performed in closest proximity to the date of PSG and the time of ABG were chosen. Data were also collected for patients who may have 
been primarily admitted with hypercapnia from underlying chronic respiratory failure if they underwent elective NCS during that hospitalization.

Ib. Exclusion criteria:

Patients who underwent:

1. Cardiac surgery

2. Thoracic surgery

3. Surgery for upper airway or tracheostomy

4. $\mathrm{AHI}<5$

II. Definition of main postoperative outcomes:

An EMR review was performed to identify postoperative complications including prolonged intubation, respiratory failure, reintubation, hypoxemia, tracheostomy, , heart failure and death from the time of surgery until discharge. These data were obtained from EMR, operative notes, post-anesthetic care unit records and discharge summary notes. Postoperative RF was defined as need for prolonged mechanical ventilation $(>24 \mathrm{~h})$, need for endotracheal reintubation, or tracheostomy. Postoperative CHF was defined as new pulmonary edema, elevated JVP $>10$ $\mathrm{mmHg}$, use of diuretic or afterload/preload reducing agents, or physician documentation of CHF. Postoperative MI was defined as appearance of new Q waves $>0.04 \mathrm{~s}$ wide and $1 \mathrm{mV}$ in depth accompanied by elevated levels of troponin T $(\geq 0.03 \mathrm{ng} / \mathrm{ml})$ and creatine kinase-MB $(>100 \mathrm{IU} / \mathrm{l})$.

III. Statistical analysis: 
Categorical variables were described as numbers and proportions. Continuous variables were described as mean (standard deviation $[\mathrm{SD}]$ ) or median (interquartile range [IQR]). Comparisons between hypercapnic OSA and OSA groups were done with the Chi square or Fisher exact test for categorical variables and the t-test or Wilcoxon rank sum test for continuous variables. Comparisons among three groups were done with the Chi square test and Kruskal Wallis test, respectively. The associations between the type of patient (hypercapnic OSA vs. OSA) or the determinants of OHS (BMI, AHI) and individual postoperative outcomes were evaluated with multivariable logistic or linear regression models for dichotomous or continuous outcomes, respectively. Variables included in multivariable models were age, gender, smoking, preoperative positive airway pressure (PAP) use, type of anesthesia, and history of cardiovascular and respiratory disease. A $\mathrm{p}<0.05$ was considered statistically significant. SAS 9.2 (Cary, NC) was used for all analyses.

\section{RESULTS}

A total of 1800 patients with $\mathrm{BMI} \geq 30$ who underwent PSG, NCSs and ABGs on more than one occasion were identified. A total of 194 patients met criteria for possible or definite OHS per study protocol. Of these $139(72 \%)$ carried the diagnosis of OSA at the time of elective surgery and the remaining (28\%) had OSA diagnosed by PSG within 1-5 years after surgery. Another cohort of 325 had OSA around the time of NCS but either did not meet the ABG criteria for OHS or did not have ABG drawn at any time during the course of treatment. This group was used as controls (OSA group).

Identification of OHS within the Cohort 
Of the 194 patients identified in the cohort, 117 patients had complete data on PFT. Among these cases 35 patients met the criteria for COPD on PFT (FEV1/FVC $<70 \%$ ) and one patient met the criteria of very severe restrictive disease $(\mathrm{FVC}<30 \%)$. Another 81 patients in the cohort did not meet criteria for COPD (FEV1/FVC>70\%). These cases were identified as 'Definite OHS'. The remaining 77 patients had either missing or no PFT data and were identified as 'possible OHS' (Figure 1). Among the entire cohort of 194 patients a total of 112 (57\%) patients met our criteria for obesity hypoventilation with hypercapnia at the time of elective surgery.

Preoperative morbidity and postoperative outcomes

Patients with definite or possible OHS were older and more likely to be male with hypertension, DM, CAD, CHF, CRF,COPD, atrial fibrillation or flutter, pulmonary hypertension and stroke, compared to patients with OSA (Table 1). General anesthesia (GA) was used less often in patients known or suspected to have OHS prior to NCS $69 \%$ vs. $82 \%(\mathrm{p}<0.0001)$. MAC/ MAC+ local anesthesia was used more often in patients with known or suspected OHS (17\% vs. 2\%) (not statistically significant). Patients with hypercapnia from definite or possible OHS, and overlap syndrome were more likely to develop postoperative respiratory failure [OR: 10.9 (95\% CI 3.7-32.3), $\mathrm{p}<0.0001]$, Postoperative heart failure $(\mathrm{p}<0.0001)$, prolonged intubation [OR: 5.4 (95\% CI 1.9-15.7), $\mathrm{p}=0.002)$, postoperative ICU transfer (OR: 3.8 (95\% CI 1.7-8.6), $\mathrm{p}=0.002$ ]; higher ICU (beta coefficient: 0.86; SE: 0.32, p=0.009) and hospital length of stay (beta coefficient: 2.94; SE: 0.87, $\mathrm{p}=0.0008$ OR) (Table 2). Among the clinical determinants of OHS, neither BMI nor AHI showed associations with any postoperative outcomes in univariable or multivariable regression analyses (Table 3$)$. In obese patients $(\mathrm{BMI} \geq 30)$ with $\mathrm{OSA}$ the presence of hypercapnia regardless of whether it was a consequence of obesity hypoventilation or 
associated COPD seemed to contribute the most to poor postoperative outcomes compared to patients with OSA without hypercapnia. We also explored the association between OSA severity categories (mild, moderate and severe based on the AHI) and outcomes and found no association (data not shown).

\section{DISCUSSION}

Amongst patients with OSA as diagnosed by PSG, significantly worse postoperative outcomes were noted if the patients were previously known to be hypercapnic based from OHS with or without overlap syndrome. In our experience this is the first study that reports perioperative outcomes in patients with known or suspected OHS. The only other time postoperative outcomes have been reported among patients with high likelihood of OHS is with the use of obesity surgery mortality risk score (OS-MRS) in patients undergoing bariatric surgery. The OS-MRS assigns 1 point to each of five preoperative variables namely: male gender; $\mathrm{BMI}>50$; $\mathrm{PH}$; OHS; prior thromboembolism, or presence of inferior vena cava (IVC) filter among patients undergoing bariatric surgery. ${ }^{6}$ Mortality rates ranged from $0.2 \%$ (in low risk class: $0-1$ morbidity) to $2.4 \%$ (among high risk class: $4-5$ co-morbidities). We have previously reported higher likelihood of postoperative complications especially respiratory failure (44\% vs $2.6 \%$ ) compared to eucapnic OSA.

Our study demonstrates that compared to patients with OSA, patients with presumed or definite OHS have higher associated medical morbidities as shown previously. ${ }^{7,8}$ Additionally, although we have demonstrated the association of preoperative hypercapnia (regardless of contributing etiology) with adverse postoperative outcomes, we cannot say whether the hypercapnia by itself or the associated imposed severe hypoxia is the causal factor for worse 
postoperative outcomes in patients with OHS. Borel et al. have outlined hypoxemia induced activation of inflammatory cascade, endothelial dysfunction and organ dysfunction in patients with OHS. ${ }^{9}$ Although there are numerous reports of the presence of OSA as a risk factor for postoperative complications, its severity as measured by AHI has not been shown to correlate with postoperative complications. ${ }^{10,11,12} \mathrm{BMI}$ on the other hand has been more controversial as posing any kind of perioperative risk. ${ }^{13,14}$ Lastly, it is possible that the lower incidence of postoperative respiratory failure in our current OSA cohort (2\%) compared to our previous study cohort $(4.9 \%)^{11}$, may be most likely due to re-classification of some OSA patients to OHS over the years from 2002 - 2013. Although it is possible that the majority of respiratory complications in patients with OSA undergoing non-cardiac surgery are dominated by the presence of underlying hypercapnia, the incidence of ICU transfer $(6 \%)$ and reintubation $(2 \%)$ remained unchanged in the OSA groups in both studies..

In our study poor outcomes were noted among patients with OHS or overlap syndrome, regardless of preferentially lesser use of GA among patients known or suspected to have OHS or overlap syndrome. We propose that prior diagnosis or suspicion of OHS must have possibly led to lesser use of GA among this group of patients compared to those with OSA alone. Until now, however, there are no data supporting this practice and this may represent a general sense of caution on the part of the anesthesiologist to minimize cardiopulmonary complications. The ASA advisory on preoperative management has recommended preferred use of regional anesthesia over GA among patients known to have OSA. ${ }^{15}$ Given that recommendation we are still surprised by the frequent use of GA $(82 \%)$ among patients with OSA in this study although not all patients were known to have OSA at the time of surgery. In their recently revised guidelines however, the ASA recommends preferred use of general anesthesia with a secure airway over 
deep sedation without a secure airway, particularly for procedures that may mechanically compromise the airway. Memtsoudis et al reported that the use of neuraxial anesthesia has been associated with a decreased rate of major complications among patients with OSA. ${ }^{16}$

The more crucial issue we want to emphasize is that most patients in our study were not known to have a diagnosis of OHS at the time of elective NCS. OHS is characterized by a triad of chronic daytime hypercapnia $\left(\mathrm{PaCO}_{2} \geq 45 \mathrm{~mm} \mathrm{Hg}\right)$, sleep disordered breathing and obesity with a BMI $>30 \mathrm{~kg} / \mathrm{m}^{2}{ }^{3}$ ABG measurements are important for confirming chronic daytime diurnal hypercapnia, however these often cannot be obtained in routine outpatient preoperative settings. Moreover, the diagnosis of OHS can only be established after excluding other possible causes of hypercapnia like severe obstructive airway disease, severe kyphoscoliosis or interstitial lung disease and neuromuscular disorders. Given these practical difficulties in establishing the diagnostic cohort there are no studies till date to report postoperative outcomes among patients with OHS.

Based on our results, we suggest wherever postoperative respiratory failure occurs in an obese patient with OSA and without other explanation the possibility of sleep related hypoventilation should be considered. Obese patients (mean BMI 39) known to have severe OSA (mean AHI: 64) and restrictive chest mechanics (pred FEV $1<71 \%$ and pred $\mathrm{FVC}<85 \%$ ) are more likely to have OHS. ${ }^{1}$ In a cohort of obese patients referred to the sleep lab for suspected OSA, a serum bicarbonate threshold of $27 \mathrm{meq} / \mathrm{L}$ was $92 \%$ sensitive in predicting hypercapnia on $\mathrm{ABG} .{ }^{3}$ Since $\mathrm{BMI}$ in that range is invariably associated with restrictive lung mechanics; diurnal oxygen desaturations $<90 \%$ (corresponding $\mathrm{PaO}_{2}<60-65 \mathrm{mmHg}$ ) and serum bicarbonate $>27 \mathrm{mEq} / \mathrm{L}$ (in absence of any other explanation) help increase the suspicion for diurnal hypercapnia which may then be confirmed by obtaining an ABG before the patient goes for any 
kind of surgery.(Figure 2). Recent data however, propose a spectrum of OHS among obese patients with only elevated serum bicarbonate and no diurnal hypercapnia. ${ }^{17}$ Also end-tidal $\mathrm{CO}_{2}$ where possible can be used as a substitute for ABG especially in the latter group. ${ }^{18}$

Among obese patients who have not been previously tested for OSA at the time of surgery, the STOP-Bang questionnaire is a validated screening tool; however, at scores $>3$ it loses the specificity for moderate (43\%) and severe OSA (37\%). Recently, Chung et al showed that addition of serum bicarbonate $>28 \mathrm{mmol} / \mathrm{L}$ increases the specificity of all OSA to $85.2 \%$ and that of severe OSA to $79.4 \% .{ }^{19}$ Higher AHI has been reported among patients with OHS compared to those with eucapnic OSA (MD:12.51, 95\% CI:6.59-18.44; $\mathrm{p}<0.0001$ ). ${ }^{1}$ Hence, if OSA is suspected in the obese preoperative patients on the basis of clinical signs and symptoms and a STOP-Bang score, serum bicarbonate $>27$ meq/L should prompt preoperative an evaluation with PSG before elective NCS, whenever possible. (Figure 2).

The most important limitation of our study is that OHS was for the most part unrecognized at the time of surgery. Although all of our cohort participants were obese (BMI $\geq$ 30), some of them were diagnosed with OSA within a certain time frame after surgery and suspicion of OHS rested on hypercapnia based on ABG drawn in relation to NCS as outlined in the inclusion criteria for this study. The best way to establish these outcomes is by way of a prospective study where ABGs can be routinely drawn on suspected patients before surgery which will require preoperative and postoperative management of hypercapnia and possible reduction in adverse postoperative outcomes. This in fact is the main point of our observational data as currently, ABG even among obese patients are obtained only when significant desaturations are noted or patients get symptomatic before surgery. Second, all of our OSA population did not have ABGs drawn so it is possible that some cases of OHS may have existed 
in the OSA group. But assuming that happened, our study would show even worse outcomes among the OHS cohort compared to patients with OSA alone. Third, we also did not have pulmonary function data on all patients so contributions from severe restrictive lung disease and underestimation of the role of undiagnosed obstructive disease are possible. Lastly, our outcomes are limited to the hospital course until discharge after the patient had NCS. Given that OHS is a chronic condition with dismal outcome, we cannot comment on the impact of NCS on survival at 6 months or 1 year in patients with known or suspected OHS.

\section{CONCLUSIONS}

Among patients with OSA a higher number of medical morbidities are known to be associated with those that have OHS compared to OSA alone. Consequently a higher number of postoperative complications are expected in this group, regardless of the patient's BMI or AHI. The risk and frequency of postoperative complication is also higher in patients with OSA and COPD (overlap syndrome), and appears to be no different than that associated with OHS.

\section{Acknowledgments:}

Author's contributions: RK conceived the study, performed data collection, analysis and interpretation of data and wrote the manuscript; LSA helped with study design, interpreted data and contributed to the manuscript; $\mathrm{PB}, \mathrm{HP}, \mathrm{AR}$ and $\mathrm{AD}$ performed data collection; AVH interpreted the statistical analysis and contributed to the manuscript. All authors approved the final draft of the manuscript. RK takes responsibility for the content of the manuscript, including the data and its analysis. 


\section{References}

1. Kaw R, Hernandez AV, Walker E et al. Determinants of Hypercapnia in Obese patients with Obstructive Sleep Apnea. A Systematic review and Meta-Analysis of Cohort studies. Chest. 2009; 136(3):787-796.

2. Lecube A, Sampol G, Lloberes P et al. Asymptomatic sleep disordered breathing in premenopausal women awaiting bariatric surgery. Obes Surg 2010; 20: 454-461.

3. Mokhlesi B, Tulaimat A, Faibussowitsch I et al. Obesity hypoventilation syndrome: Prevalence and predictors in patients with obstructive sleep apnea. Sleep Breath 2007;11: 117-124.

4. Lung function testing: selection of reference values and interpretative strategies. American Thoracic Society. The American review of respiratory disease. 1991;144(5):1202-1218.

5. Celli BR, MacNee W, Force AET. Standards for the diagnosis and treatment of patients with COPD: a summary of the ATS/ERS position paper. The European respiratory journal. 2004;23(6):932-946.

6. DeMaria EJ, Murr M, Byrne TK et al. Validation of the Obesity surgery mortality risk score in a multi-center study proves it stratifies mortality risk in patients undergoing gastric bypass for morbid obesity. Ann Surg 2007. 246; 578-82.

7. Berg G, Delaive K, Manfreda J, Waldd R, Kryger MH. The use of health care resources in obesity hypoventilation syndrome. Chest 2001; 120: 377-383.

8. Nowbar S, Burkart KM, Gonzales R, et al. Obesity-associated hypoventilation in hospitalized patients: prevalence, effects, and outcome. The American journal of medicine. 2004;116(1):1-7. 
9. Borel JC, Roux-Lombard P, Tamisier R, et al. Endothelial dysfunction and specific inflammation in obesity hypoventilation syndrome. PloS one. 2009;4(8):e6733.

10. Liao P, Yeneswaran B, Vairavanathan S, Zilberman P, Chung F. Postoperative complications in patients with obstructive sleep apnea: a retrospective matched cohort study. Can J Anaseth. 2009; 56(11): 819-28.

11. Kaw R, Pasupuleti V, Walker E, Ramaswamy A, Foldvary-Schafer N. Postoperative complications in patients with obstructive sleep apnea. Chest 2012; 141(2): 436-41.

12. Weingarten TN, Flores AS, McKenzie JA, et al. Obstructive sleep apnoea and perioperative complications in bariatric patients. British journal of anaesthesia. 2011;106(1):131-139

13. Smetana GW. Preoperative pulmonary evaluation. NEJM. 1999; 340: 937-944.

14. Mullen JT, Moorman DW, Davenport DL. The obesity paradox: Body mass index and outcomes in patients undergoing nonbariatric general surgery. Annals of surgery. 2009; 250: 166-172.

15. Gross JB, Bachenberg KL, Benumof JL, et al ; American Society of Anesthesiologists Task Force on Perioperative Management . Practice guidelines for the perioperative management of patients with obstructive sleep apnea: a report by the American Society of Anesthesiologists Task Force on Perioperative Management of patients with obstructive sleep apnea. Anesthesiology. 2006;104: 1081 - 1093.

16. Memtsoudis SG, Stundner O, Rasul R, et al. Sleep apnea and total joint arthroplasty under various types of anesthesia: a population-based study of perioperative outcomes. Reg Anesth Pain Med. 2013;38:274-81.

17. Manuel AR, Hart N, Stradling JR. Is a raised bicarbonate, without hypercapnia, part of the physiologic spectrum of obesity-related hypoventilation? Chest. 2015;147(2):362-368. 
18. Jaimchariyatam N, Dweik R, Kaw R, Aboussouan L. Polysomnographic Determinants of Nocturnal Hypercapnia in Patients with Sleep Apnea. Journal of Clinical Sleep Medicine. 2013; 9(3): 209-15.

19. Chung F, Chau E, Yang Y et al. Serum bicarbonate level improves specificity of STOP-Bang screening for obstructive sleep apnea. Chest 2013; 143(5): 1284-1293.

20. Kaw R, Argalious M, Aboussouan LS, Chung F. Obesity Hypoventilation Syndrome and Anesthesia Considerations. Sleep Medicine Clinics 2014; 9(3): 399-407. 
Table 1: Baseline characteristics of cases and controls

\begin{tabular}{|c|c|c|c|}
\hline Variables & $\begin{array}{l}\text { Hypercapnic } \\
\text { OSA }(n=194)\end{array}$ & $\begin{array}{l}\text { OSA } \\
(n=325)\end{array}$ & $\mathbf{P}$ \\
\hline Age, mean (SD) & $62.7(11.4)$ & $57.7(12.6)$ & $<0.0001$ \\
\hline Male, n (\%) & $86(49)$ & $142(45)$ & 0.5 \\
\hline AHI, mean (SD) & $42.27(31.3)$ & $37.08(29.8)$ & 0.08 \\
\hline BMI, mean (SD) & $41.35(9.5)$ & $38.03(11.0)$ & 0.001 \\
\hline Preoperative PAP use, n (\%) & $57(24)$ & $8(2)$ & $<0.0001$ \\
\hline History of CAD, n (\%) & $87(46)$ & $64(20)$ & $<0.0001$ \\
\hline History of MI, n (\%) & $26(14)$ & $9(3)$ & $<0.0001$ \\
\hline History of CHF, n (\%) & $81(43)$ & $30(9)$ & $<0.0001$ \\
\hline History of COPD, n (\%) & $83(45)$ & $39(12)$ & $<0.0001$ \\
\hline History of Asthma, n (\%) & $38(40)$ & $57(18)$ & 0.4 \\
\hline History of AF or Flutter, n (\%) & $42(22)$ & $21(6)$ & $<0.0001$ \\
\hline History of Pulmonary hypertension, $\mathrm{n}(\%)$ & $14(8)$ & $8(2)$ & 0.006 \\
\hline History of hypertension, $\mathrm{n}(\%)$ & $157(83)$ & $221(68)$ & 0.0003 \\
\hline History of diabetes, $\mathrm{n}(\%)$ & $101(53)$ & $96(30)$ & $<0.0001$ \\
\hline History of chronic renal failure, n (\%) & $54(29)$ & $18(6)$ & $<0.0001$ \\
\hline History of stroke, $\mathrm{n}(\%)$ & $25(13)$ & $17(5)$ & 0.001 \\
\hline $\begin{array}{l}\text { Smoking, n (\%) } \\
\text { Current } \\
\text { Past } \\
\text { No }\end{array}$ & $\begin{array}{l}16(9) \\
80(43) \\
90(48)\end{array}$ & $\begin{array}{l}14(4) \\
85(26) \\
226(70)\end{array}$ & $<0.0001$ \\
\hline $\begin{array}{l}\text { Type of Surgery, n (\%) } \\
\text { General surgery } \\
\text { Orthopedic surgery } \\
\text { Vascular surgery } \\
\text { Neurological surgery } \\
\text { Urological surgery } \\
\text { Colorectal surgery }\end{array}$ & $\begin{array}{l}55(28) \\
42(22) \\
37(19) \\
22(11) \\
21(11) \\
7(4)\end{array}$ & $\begin{array}{l}131(40) \\
83(26) \\
17(5) \\
25(8) \\
18(6) \\
15(5)\end{array}$ & \\
\hline
\end{tabular}




\begin{tabular}{|l|l|l|l|}
\hline $\begin{array}{l}\text { Gynecological surgery } \\
\text { Other }\end{array}$ & $\begin{array}{l}4(2) \\
6(3)\end{array}$ & $\begin{array}{l}27(8) \\
9(3)\end{array}$ & \\
\hline $\begin{array}{l}\text { Type of Anesthesia, n (\%) } \\
\text { General }\end{array}$ & $126(69)$ & $256(82)$ \\
Spinal & $20(11)$ & $31(10)$ \\
Epidural, Spinal + Epidural & $4(2)$ & $16(5)$ & $3(1)$ \\
PVB & $2(1)$ & $6(2)$ & \\
MAC, Local + MAC & $31(17)$ & & \\
\hline Obstructive Sleep Apnea Severity (AHI Score), n & & & \\
(\%) & $30(15)$ & $84(26)$ & \\
$5-15$ & $78(40)$ & $151(46)$ & 0.0001 \\
$>15-30$ & & & 0.17 \\
$>30$ & & & \\
\hline
\end{tabular}

$\mathrm{CAD}=$ coronary artery disease $\mathrm{CHF}=$ congestive heart failure; $\mathrm{COPD}=$ chronic obstructive pulmonary disease; $\mathrm{HF}=$ heart failure; $\mathrm{MAC}=$ monitored anesthesia care; $\mathrm{MI}=$ myocardial infarction; $\mathrm{PVB}=$ paravertebral block; ICU = intensive care unit; $\mathrm{SD}=$ standard deviation 
Table 2: Adjusted Risk of Postoperative Outcomes in Patients with Definite, Possible OHS and Overlap Syndrome vs. OSA patients*

\begin{tabular}{|l|l|l|l|l|l|}
\hline Variables & $\begin{array}{l}\text { Hypercapnic OSA } \\
(\mathbf{n = 1 9 4})\end{array}$ & $\begin{array}{l}\text { OSA } \\
(\mathbf{n = 3 2 5})\end{array}$ & $\begin{array}{l}\text { Odds } \\
\text { Ratio }\end{array}$ & $\mathbf{9 5 \%}$ CI & $\boldsymbol{P}$ \\
\hline $\begin{array}{l}\text { Postoperative respiratory } \\
\text { failure, n (\%) }\end{array}$ & $39(21)$ & $8(2)$ & 10.9 & $(3.7-32.3)$ & $<0.0001$ \\
\hline Postoperative HF, n (\%) & $15(8)$ & 0 & 5.4 & $(1.9-15.7)$ & 0.002 \\
\hline $\begin{array}{l}\text { Postoperative prolonged } \\
\text { intubation, n (\%) }\end{array}$ & $24(13)$ & $12(4)$ & 3.1 & $(0.6-15.3)$ & 0.2 \\
\hline $\begin{array}{l}\text { Postoperative reintubation, n } \\
(\%)\end{array}$ & $12(6)$ & $5(2)$ & 1.7 & $(0.2-13.4)$ & 0.6 \\
\hline $\begin{array}{l}\text { Postoperative tracheostomy, n } \\
(\%)\end{array}$ & $4(2)$ & $3(1)$ & 3.8 & $(1.7-8.6)$ & 0.002 \\
\hline $\begin{array}{l}\text { Postoperative ICU transfer, n } \\
(\%)\end{array}$ & $41(21)$ & $19(6)$ & 10.9 & $(3.7-32.3)$ & $<0.0001$ \\
\hline Death at 30 days, n (\%) & $2(1)$ & 0 & Scarce number of events & \\
\hline Death at 1 year, n (\%) & $10(5)$ & $2(0.6)$ & 0.9 & $(0.1-7.5)$ & 0.9 \\
\hline Variables & $\begin{array}{l}\text { Hypercapnic OSA } \\
(\mathbf{n = 1 9 4 )}\end{array}$ & $\begin{array}{l}\text { OSA } \\
(\mathbf{n}=\mathbf{3 2 5})\end{array}$ & $\begin{array}{l}\text { Beta- } \\
\text { coefficient }\end{array}$ & $\begin{array}{l}\text { Standard } \\
\text { error }\end{array}$ & $\boldsymbol{P}$ \\
\hline $\begin{array}{l}\text { Postoperative ICU length of } \\
\text { stay, days (IQR) and mean (SD) }\end{array}$ & $\begin{array}{l}0(0-0) \\
0.12(0.93)\end{array}$ & $\begin{array}{l}0(0-0) \\
1.04(3.8)\end{array}$ & 0.86 & 0.32 & 0.009 \\
\hline $\begin{array}{l}\text { Hospital length of stay, days } \\
\text { (IQR) and mean (SD) }\end{array}$ & $\begin{array}{l}5(3-9) \\
7.3(8.2)\end{array}$ & $\begin{array}{l}0(0-4) \\
2.8(5.1)\end{array}$ & 2.94 & 0.87 & 0.0008 \\
\hline
\end{tabular}

$\mathrm{HF}=$ heart failure; ICU = intensive care unit; IQR = interquartile range; $\mathrm{SD}=$ standard deviation $\mathrm{ICU}=$ intensive care unit, PAP, positive airway pressure; $\mathrm{PH}$, pulmonary hypertension; PSG, polysomnography; $\mathrm{SPO}$, oxygen saturation via pulse oximetry. *Adjusted for all patient variables in Table 1. 
Table 3. Independent effect of BMI and AHI on Postoperative outcomes in patients with Definite/possible OHS and Overlap Syndrome

\begin{tabular}{|c|c|c|c|c|}
\hline Postoperative Outcomes & $\begin{array}{c}\text { BMI } \\
\text { Adjusted Statistic** } \\
\end{array}$ & p-value & $\begin{array}{r}\text { AHI* } \\
\text { Adjusted Statistic** } \\
\end{array}$ & p-value \\
\hline Postop Respiratory Failure & $\begin{array}{l}0.99(0.95,1.03) \\
\end{array}$ & & $101.01(0.99,1.02)$ & \\
\hline Postop Heart Failure & $0.94(0.85,1.04)$ & & $1.00(0.98,1.02)$ & \\
\hline $\begin{array}{l}\text { Postop prolonged } \\
\text { intubation }\end{array}$ & $1.01(0.97,1.05)$ & & $1.00(0.99,1.02)$ & \\
\hline Postop re-intubation & $0.99(0.93,1.05)$ & & $1.01(0.99,1.02)$ & \\
\hline Postop ICU transfer & $0.99(0.96,1.02)$ & & $1.01(1.00,1.02)$ & \\
\hline $\begin{array}{l}\text { Postop ICU length of stay } \\
\text { (beta }+/-\mathrm{SE} \text { ) }\end{array}$ & $0.0073 \pm 0.01$ & 0.80 & $0.009 \pm 0.004$ & 0.006 \\
\hline $\begin{array}{l}\text { Hospital length of stay } \\
\text { (beta }+/-\mathrm{SE} \text { ) }\end{array}$ & $0.006 \pm 0.03$ & 0.90 & $0.009 \pm 0.01$ & 0.40 \\
\hline
\end{tabular}

*Models were adjusted for BMI

** Statistic expressed as OR $(95 \% \mathrm{CI})$ unless detailed otherwise

ICU: Intensive care unit 
Figure Legends:

Figure 1: Flow diagram for OHS cohort identification and patient selection

Figure 2: Preoperative decision tree in patients with suspected obesity hypoventilation syndrome (OHS). Adapted figure used with permission from Kaw R, $2014^{20}$ 


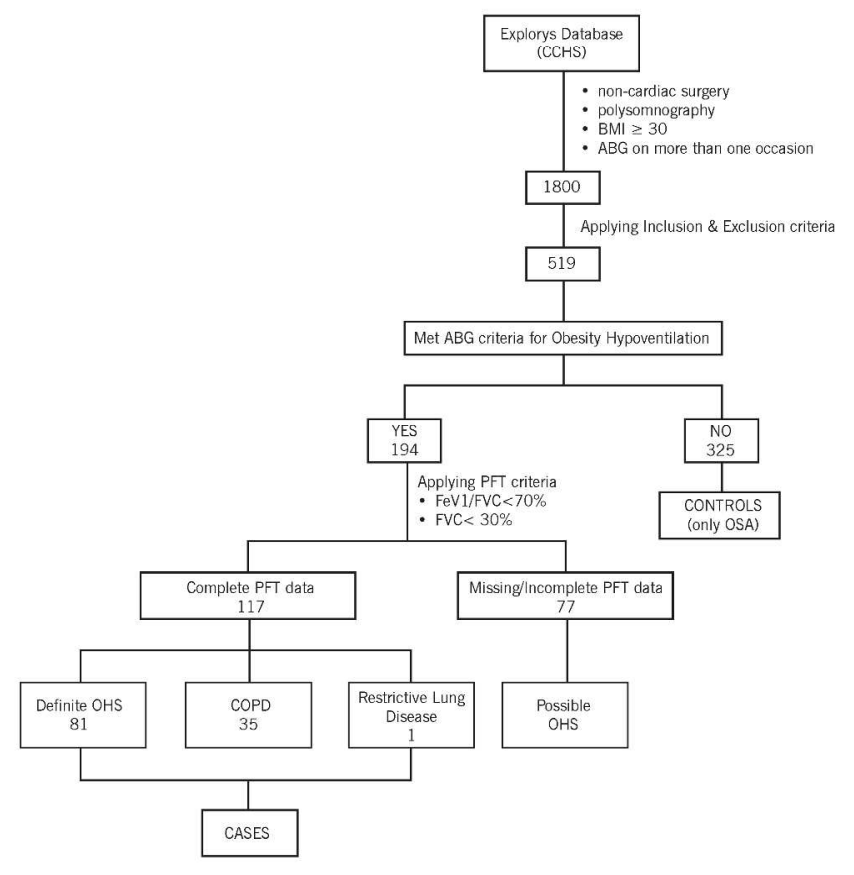

$279 \times 215 \mathrm{~mm}(300 \times 300$ DPI $)$

Downloaded From: http://journal.publications.chestnet.org/ by a Cleveland Clinic User on 06/16/2015 


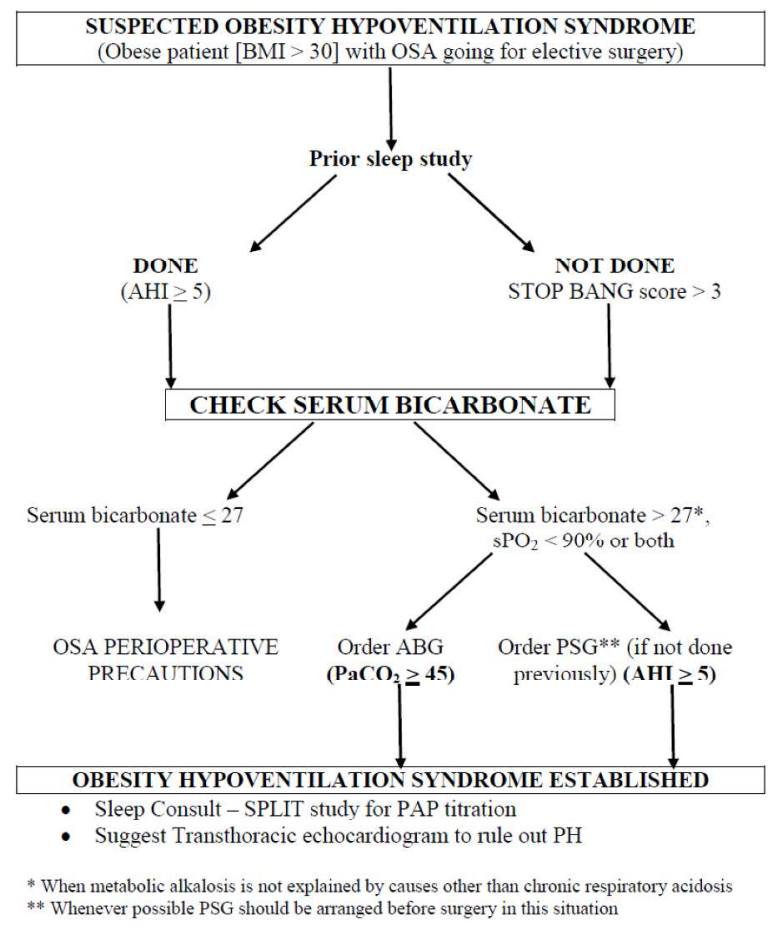

$254 \times 190 \mathrm{~mm}(300 \times 300 \mathrm{DPI})$ 